\title{
FACTORS CONTRIBUTING TO DYSPHEMISTIC EFFECT. TYPES OF DYSPHEMISM
}

\author{
Olga N. Prokhorova, ${ }^{1}$ \\ Igor V. Chekulai, ${ }^{2}$ \\ Elena V. Pupynina, ${ }^{3}$ \\ Ekaterina F. Bekh ${ }^{4}$
}

\begin{abstract}
This paper examines ways to divide dysphemisms into groups. It argues that there is need to take into account several factors common for communicative situations in which dysphemisms are used. Research shows that they are the speaker, the referent, the intention of the speaker, language resources. According to language recourses used to achieve dysphemistic effect words and phrases are divided into those that have contextual or dictionary dysphemistic meaning. They fall into two groups according to animate or inanimate referent. Two other factors are pragmatic. They influence the use of dysphemism in different groups
\end{abstract} determining their characteristics in a particular communicative situation.

\section{Introduction.}

\section{Arbitrary correspondence} between the meaning and the form in language gives speakers opportunity to control their lexical choices and effects their linguistic behaviour produces. To make their phrases about unpleasant, embarrassing or offensive things sound positive speakers use euphemisms. In contrast, dysphemisms make speech

\footnotetext{
${ }^{1}$ National Research University "Belgorod State University" / "BelSU”, Russia, 308015, Belgorod, Studencheskaya Street, 17

2 National Research University "Belgorod State University" / "BelSU", Russia, 308015, Belgorod, Studencheskaya Street, 17

${ }^{3}$ National Research University "Belgorod State University" / "BelSU”, Russia, 308015, Belgorod, Studencheskaya Street, 17

4 National Research University "Belgorod State University” / "BelSU”, Russia, 308015, Belgorod, Studencheskaya Street, 17
} 
straightforward, harsh or even offensive.

This paper aims to address the question about classification of dysphemisms that could account for different criteria. Traditional approach defines types of dysphemisms on the basis of one main property, usually lexical or stylistic one. Besides, there is difficulty in marking dysphemism apart from vulgarism and jargonism, slang and even dysphemism [1]. The reason is that these groups overlap lexically. However, some linguists argue that differences lie in the purpose of their use rather than in the words themselves [2].

In general, the term "euphemism" is more frequent than dysphemism. There is a large body of literature describing types of euphemisms and their role in everyday life. However, far less attention has been paid to dysphemisms.

Simple quantitative analysis of the use of these terms with Google Books Ngram Viewer shows disproportion between the numbers of occurrences (method section of this paper gives detailed description of the instrument used for the quantitative analysis). The graph below shows that there is significant difference between the trends in the use of two terms from 1800 to 2008 (Fig. 1). There was a steady increase in the number of euphemism occurrences that peeked after 1990 and fell slightly between 1994 and 2008. The use of the term "dysphemism" increased slightly after 1976 and remained at very low levels until 2008.

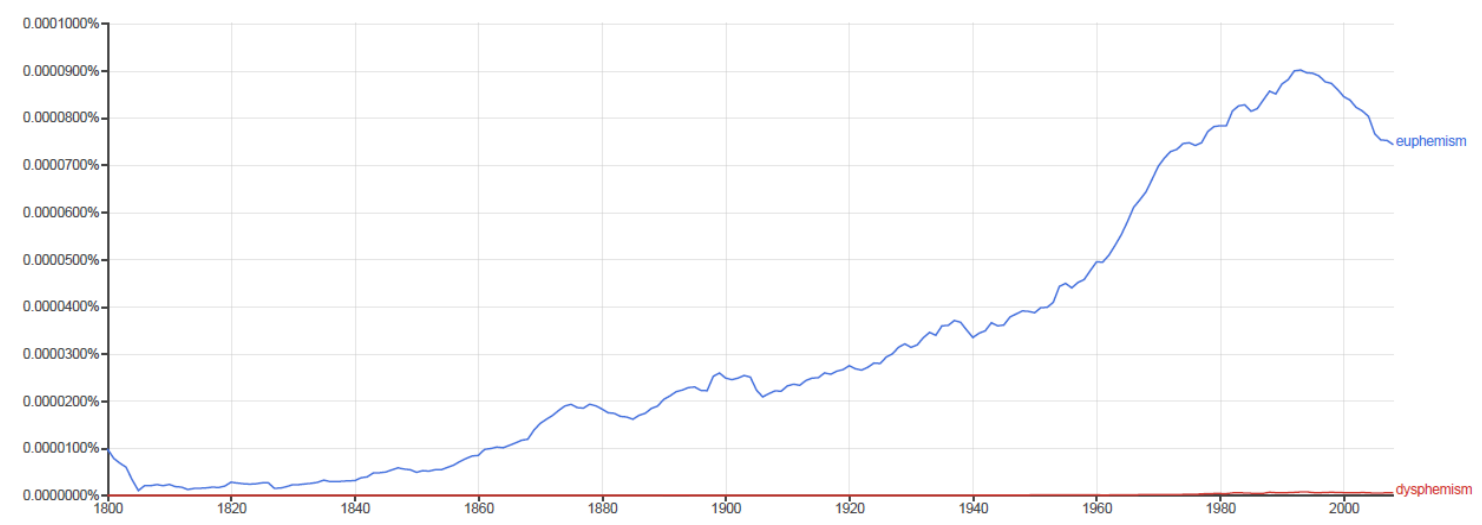

Figure 1. The trends in the use of "euphemism" and "dysphemism" according to the Google Books Ngram Viewer 
The etymology of the word dysphemism reveals that the first morpheme of the word, which is "dis-" means "bad, abnormal, or difficult". It originates from ancient Greek. The second morpheme "-fem-" means "speech, voice or utterance". Dysphemisms make utterances sound deprecating, derogatory or insulting. They add negative connotation to a statement. In literature, this figure of speech is used to characterize heroes or convey their disapproving, rude or disparaging attitude to others. "The use of bad language is a complex social phenomenon" [3].

Some authors (e.g., G. Hughes,

\section{E. A. Sidelnikova} and

\section{S. V. Serebryakova,}

A. N. Rezanova) have attempted to draw distinctions between different classes of dysphemisms. G. Hughes notes that there are hardly any aspects of life free from dysphemism. The author writes about dysphemisms for sensitive and embarrassing topics such as death, dysphemisms against romantic and heroic myths, and dysphemisms in insults [4]. E. A. Sidelnikova and S. V. Serebryakova present an account of dysphemisms in financial and economic discourse [5]. L. N. Mosievich argues that the use of dysphemism is contingent on social and cultural factors, which means that the quantity of dysphemisms may be indicative of important social issues. The author defines several semantic domains in which these words are abundant. They are social status (scraper, zillionaire), psychological state (halfwit), and human biology (to croak). [6].

According to A. N. Rezanova, there are five lexical classes of dysphemisms. They are 1) dysphemisms for death, disease, ascription of physical and mental inadequacy; 2) dysphemisms related to the wide sphere of crime; 3) dysphemisms for human vices; 4) dysphemisms for ethnicity; 5) dysphemisms referring to religious taboos [7].

It is evident that dysphemisms are divided into classes presented above according to spheres of personal and social life that become objects of reference in the meaning of dysphemism. This paper proposes to classify dysphemisms on the bases of more that one criterion taking into consideration 
different aspects of situations in which they are used.

Method.

This research employs quantitative and qualitative methods. The first one implies the use of the Google Books Ngram Viewer [8]. This is a tool for searching words and sequences of words in a large corpus of books and building graphs showing their frequencies within certain periods. Received timelines show changes in the use of words, which may be indicative of changes in importance of concepts that these words represent. Qualitative method implies semantic and pragmatic analysis of dysphemism and contexts in which they occur.

\section{Results and Discussion.}

Analyzing communicative situations in which dysphemisms occur we found that there are several aspects common for different situations. We suggest that they should be taken in account in classification of dysphemisms. They may be presented in the form of questions. Who uses dysphemism? To who or what does it refer? What is the purpose of its use? How is dysphemistic effect achieved?

With respect to the first question, it is worth noting that there are a few cases when the speaker matters. Firstly, some dysphemisms may be frequent in the speech of a particular group of people. A useful example is the expression "class warfare" that is mostly used by conservative or wealthy people when they speak about those who fight for bridging the growing gap between the rich and the poor: "Charles Spears stood with his crucifer and torch bearers beside the coffin, feeling more like an ecclesiastical referee than a proclaimer of the Resurrection. 'What the hell's this?' Lawrence Bennett said, pointing at the pall covering his father's coffin. 'That coffin cost $\$ 50,000$. I want people to see that we care.' 'We cover the coffin to show that we are all equal in death,' the priest replied. 'That's class warfare,' Lawrence snapped." (McGavran F. Death without Taxes.)

Secondly, a word that is expected to be dysphemistic with regard to the hearer may become jocular when used by a person belonging to the group of people that this word targets at or when it is used towards close friends to 
cheer them up. Accordingly, dysphemistic meaning is contextual and depends on the set of interlocutors as in the following excerpt: "I know my best days are behind me. I made my peace with that a long time ago. I'm ready to die." "Who said anything about you dying? You're probably going to outlive us all, you old coot." I was trying to break up the mood in a way only a true friend could do. "If I do live that long, it's only to be a pain in your ass, T. K." he joked, forcing himself to sit up. My wife helped him by propping a pillow behind his neck." (Weber C. The Choir Director.)

The second question focusses on object of reference. As pointed out above, most classifications differentiate dysphemisms according to this principle. However, it is notable that they do not have a class of dysphemisms used to refer to inanimate objects. A well-known example of this category is "snail mail" that points out to slowness of the conventional postal system in comparison with electronic mail: "And poor Etta, she was nice to a stranger and caught herpes, so that was that. When Mother left off phoning, Etta and Margaret wrote letters, but you can't be too careful. When you're scared of germs after a while you start getting scared of everything that might have been near germs. You're scared of germs coming off of people and you're scared of germs getting on things like envelope glue, even though the mail person has strict instructions to put your snail mail in the De-con box outside the front door." (Reed K. Precautions.)

If the use of dysphemism is deliberate, it may serve different purposes or intentions (the third question above). Speakers resort to dysphemism to express their emotional attitude to people, things or events. In most cases it is anger, annoyance, disappointment or frustration. For example: "No. I have to go home," said Lucy, as if torn. "Why?" said Jay wildly. "Why? Your damn son?" "No, I have to be up early in the morning." (Cooper F. Jay Loves Lucy.)

In the following excerpt, dysphemism reveals feelings of the disappointed, frustrated father: "'It's an injection of cocaine mixed with heroin. It's real big boy stuff' - the senator's voice was very bitter - 'and all of that garbage is washed down with alcohol and pickled in nicotine. My son is a dying junkie, but he doesn't want to die 
alone so he's encouraging Robin-Anne to keep him company and now she's become addicted to cocaine and it won't be very long before she's smoking crack and trying speedballs." (Cornwell B. Crackdown.)

The example above illustrates the role of dysphemism in revealing the emotional attitude of the speaker towards the referent of dysphemistic word or phrase. Besides, using dysphemism speakers release their emotions as the following example shows: "A harsh breeze rattled the branches, dropping the temperature by ten degrees as tendrils of dark gray cumulonimbus overtook the sapphire sky. Swirls of black-green clouds edged the steel gray above the horizon to the east. 'Bloody hell!' Simon jumped, almost slipping down the steep incline as lightning shredded the sky and hail pelted them, icy marbles lobbed by the clouds. The air froze as the wind blasted, and incongruously, it began to snow. Hard. They made a run for Simon's BMW." (Barnett B. The Apothecary's Curse.)

Dysphemism displays speakers' disapproving or negative attitude to people, things or events. In comparison with the function of expressing emotional attitude described above, this is the case of rational evaluative attitude. It can be illustrated by the following excerpt from a magazine article: "What emerges in Kate's McMansions 101 posts in particular is that nearly all of the sins of McMansions often boil down to the same thing: violations of order, harmony, and symmetry. What makes a normal house successful is a sense of balance, with equally weighted elements and an overall sense of aesthetic cohesion. What makes a McMansion an eyesore is its jumble of eaves, columns, oversized garages, and other compounded fiascos." (Is your McMansion Haunted? Probably // Slate Magazine. 2016.)

A broad area of use of both euphemisms and dyshemisms is the topic of death and disease. This is easily explained taking into account the characteristics of the human psyche. Death and illness are tragic events, they cause fear, and therefore talking about them people want to soften negative effect downplaying concerns about them. Sometimes substitution of a blunt word for a neutral one referring to these topics allows the speaker to challenge conventional patterns of behaviour, to 
exhibit superiority and fearlessness ridiculing these events. An example is the following dialogue: "'Come on.' He eased himself out of the chair. 'What?' 'She's off now, doing the other curtains. We can whip down to the Bricklayers for a pint.' 'Should you?' 'Bloody hell, Charles. If I'm going to snuff it, I'd rather snuff it with a pint in my fist than one of their bloody mugs of Ovaltine. Come on." (Brett S. Cast, in Order of Disappearance.)

Speakers may also intend their words to be disparaging, insulting. "The most popular of the independent suggestions was to increase the budget for environmental protection and national parks. Charles Hosch of Marietta disagreed with all of our proposed uses. 'Return it to the taxpayers who earned it, you liberal slugs,' he wrote." (Tucker C. From our Readers. Responses to "Wishbook for America" // Atlanta Journal Constitution. 1995.) In this case, even neutral words can produce dysphemistic effect in some contexts.

Returning to the fourth question (How is dysphemistic effect achieved?), we have seen in examples that different linguistic and stylistic elements can form this effect. First, these are words whose lexical meaning is supposed to be dysphemistic. Secondly, context is an important factor that can turn a word having neutral or even positive dictionary meaning into dysphemistic one. In addition, there are figures of speech that establish dysphemistic tone of the utterance such as metaphor, hyperbole, simile, synecdoche and others. Finally, "stylistic discord" that $\mathrm{K}$. Allan and K. Burridge mention in their work: "an example would be where someone at a formal dinner party publicly announced 'I'm off to have a piss', rather than saying something like "excuse me for a moment'" [9, p. 240].

Having discussed what factors to take into account, we will now move on to classification of dysphemisms. We suppose that according to ways of achieving dysphemistic effect words studied can be divided into contextual and dictionary dysphemisms. The second group contains words and phrases that are always dysphemistic independent of the context. According to what or who dysphemisms refer to, there are animate and inanimate referents. The groups suggested here do not overlap. In case of the other factors discussed above, 
they do not form separate classes of dysphemisms since they are applicable to any of the groups found. The diagram showing our view of grouping dysphemisms according to the criteria described in this paper is provided below (Fig. 2).

\section{$\left.\begin{array}{l}\text { Set of interlocutors } \\ \text { Intentions / Purposes }\end{array}\right\}$}

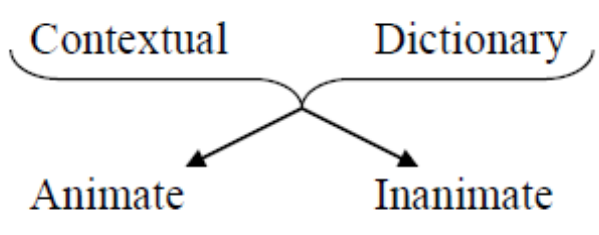

Figure 2. Groups of dysphemisms and factors that influence their use

Figure 2 provides a model of communicative situation with several pragmatic and semantic factors influencing linguistic choices of speakers.

\section{Conclusion.}

Dysphemistic

utterances

frequently occur in speech. However, frequency of the term "dysphemism" compared to "euphemism" in literature found with the help of the Google Books Ngram Viewer shows that the research to date has tended to focus on euphemism rather than on dysphemism although the latter is an important element of language.

Analysis of literature demonstrates that there have been attempts to group dysphemisms according to different criteria, mostly lexical and stylistic ones. The present study was designed to build classification of dysphemisms that could account for several factors determining dysphemistic effect of the utterance.

The results of this study indicate that there are several aspects common for different communicative situations that are important for grouping dysphemisms. They are the speaker, people, things or events that dysphemism refers to, the purpose or the intention of the speaker, language resources that are used to produce dysphemistic effects.

According to these factors, we propose groups that do not overlap. They are contextual and dictionary dysphemisms. The latter group is constituted by words and phrases that are always dysphemistic independent of the 
context. There are also dysphemisms referring to animate or inanimate entities. Such factors as the speaker and the intention of the speaker are flexible and can apply to any of the groups proposed.

\section{Acknowledgments}

This work was supported by Belgorod State National Research University (University research grant).

\section{References}

Enright, D. J., 1985. Fair of Speech: The Uses of Euphemism. Oxford: Oxford University Press.

Warren, B., 1992. What Euphemisms Tell us about the Interpretation of Words. Studia Linguistica, 46 (2): 128-172.

McEnery, T., 2006. Swearing in English. Bad Language, Purity and Power from 1586 to the Present. Abingdon: Routledge.

Hughes, G. An Encyclopedia of Swearing: The Social History of Oaths, Profanity, Foul Langauge, and Ethnic Slurs in the English-Speaking World.
Armonk: M. E. Sharpe

Sidelnikova,

E. A.

and

S. V. Serebryakova, 2017.

Kommunikativno-pragmaticheskaya i perevodcheskaya spetsifika evfemizatsii i disfemizatsii V gazetnopublitsisticheskom ekonomicheskom diskurse. Stavropol: SKFU. URL: https://rucont.ru/efd/622880.

Mosievich, L., 2009. Disfemizmy i yazykovaya kartina mira. Naukovi zapysky, 81(3): 358-362. URL: http://nbuv.gov.ua/UJRN/Nzs_2009_81 $\% 283 \% 29 \quad 88$

Rezanova, A. N., 2008. Disfemiya v angliiskom yazyke: semanticheskiye mehanizmy i pragmaticheskiye funktsii. Sankt-Peterburg.

Michel, J-B. et al., 2011. Quantitative Analysis of Culture Using Millions of Digitized Books. Science, 331(6014): 176-182.

Allan, K. and K. Burridge, 2006. Forbidden Words: Taboo and the Censoring of Language. Cambridge: Cambridge University Press. 


\section{Information about the authors}

Olga Nikolaevna Prokhorova, Doctor

of Philology, Professor, National

Research University "Belgorod State

University" / "BelSU”, Russia, 308015,

Belgorod, Studencheskaya Street, 17

prokhorova@bsu.edu.ru, +7

(4722) 245400 .

Igor Vladimirovich Chekulai, Doctor of Philology, Professor, National Research University "Belgorod State University" / "BelSU”, Russia, 308015, Belgorod, Studencheskaya Street, 17

chekulay@bsu.edu.ru, +7

(4722) 301245.

Elena Vladimirovna Pupynina, $\mathrm{PhD}$

(Philology), Associate Professor, National Research University "Belgorod State University" / "BelSU”, Russia, 308015, Belgorod, Studencheskaya Street, 17

pupynina@bsu.edu.ru, $\quad+7$ (4722) 301245.

Ekaterina Feodorovna Bekh, Instructor, National Research University "Belgorod State University" / "BelSU",
Russia, 308015, Belgorod,

Studencheskaya Street, 17

bekh@,bsu.edu.ru, +7 (4722)

301245 